Slavica

bruxellensia

\section{Slavica bruxellensia}

Revue polyphonique de littérature, culture et histoire

slaves

$10 \mid 2014$

Espace slave, espace germanique

Petra James, Bohumil Hrabal : « composer un monde blessant à coups de ciseaux et de gomme arabique »

\title{
Thibault Deleixhe
}

\section{OpenEdition}

\section{Journals}

Édition électronique

URL : http://journals.openedition.org/slavica/1567

DOI : 10.4000/slavica.1567

ISSN : 2034-6395

\section{Éditeur}

Université libre de Bruxelles - ULB

\section{Référence électronique}

Thibault Deleixhe, «Petra James, Bohumil Hrabal : " composer un monde blessant à coups de ciseaux et de gomme arabique » », Slavica bruxellensia [En ligne], 10 | 2014, mis en ligne le 10 février 2014, consulté le 22 septembre 2020. URL : http://journals.openedition.org/slavica/1567 ; DOI : https://doi.org/ 10.4000/slavica. 1567

Ce document a été généré automatiquement le 22 septembre 2020.

\section{cc) $(1) \odot$}

Les contenus de Slavica bruxellensia sont mis à disposition selon les termes de la Licence Creative Commons Attribution - Pas d'Utilisation Commerciale - Pas de Modification 3.0 France. 
Petra James, Bohumil Hrabal : " composer un monde blessant à coups de ciseaux et de gomme arabique "

Thibault Deleixhe

\section{RÉFÉRENCE}

Petra James, Bohumil Hrabal : " composer un monde blessant à coups de ciseaux et de gomme arabique », Classiques Garnier, Études de Littératures du XX et XXI ${ }^{\mathrm{e}}$ siècles, Paris, 2012, $462 \mathrm{p}$. 
1 La citation de Bohumil Hrabal retenue comme titre de cet ouvrage en résume brillamment l'objet: " composer un monde blessant " ou décrire la difficile réalité d'après-guerre, «à coups de ciseaux » - au moyen de textes découpés, «et de gomme arabique " - et des oublis inhérents à toute réalisation culturelle. Elle renferme les trois problématiques fondamentales de cette recherche sur la prose hrabalienne: Quelle mimésis? Avec

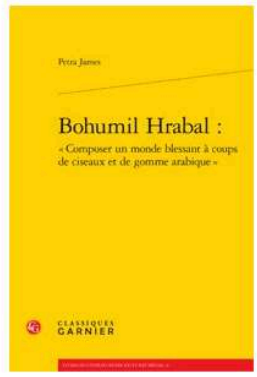
quelles techniques d'écriture? Et quel matériau littéraire (et en absence de quels autres) ? L'auteur inscrit cette étude dans une perspective comparatiste en confrontant les pratiques du collage chez Hrabal à celles des représentants du foyer parisien de la poésie expérimentale, telles que le cutup des artistes américains William S. Burroughs et Brion Gysin ou encore les textes expérimentaux de Claude Simon.

2 Bien qu'il s'agisse-là d'artistes et d'œuvres déjà soigneusement cartographiés par les études littéraires, personne n'avait à ce jour effectué ce rapprochement, pourtant suggéré dans ses textes par Hrabal lui-même. L'originalité de cette étude est donc de revenir sur les interactions ayant eu lieu entre ces milieux mais aussi et surtout d'étudier l'impact qu'auront eu leurs situations historiques respectives sur leur création littéraire et d'établir des distinctions dans le traitement qu'ils réservent aux enjeux mémoriels.

Le livre s'articule autour de deux axes. Le premier est consacré à l'identification des héritages littéraires dans lesquels puise l'écriture hrabalienne. L'auteur dresse un catalogue des courants avant-gardistes tchèques et étudie les mutations qu'ils connaissent au cours du siècle, notamment suite aux échecs de leurs programmes esthétiques n'ayant pu prévenir la barbarie des guerres mondiales. Elle met en exergue les enjeux mémoriels nationaux qui ont infléchi le développement de ces courants littéraires : alors que l'Europe occidentale et orientale expérimentent des esthétiques radicalement neuves, faisant table rase d'un patrimoine discrédité, l'Europe centrale ne peut se résoudre à s'amputer d'une tradition culturelle qui a longtemps constitué le socle de nations à l'indépendance fraichement recouverte. C'est cette mémoire sauvegardée qui servira de matériau privilégié aux auteurs qui lui feront suite, Hrabal au premier chef.

4 Le second axe est dédié à la trajectoire esthétique de Hrabal au cours des années 1950-1980. Profitant de l'habitude de Hrabal de retravailler ses textes, l'auteur en compare les versions et suit pas à pas les mutations stylistiques, depuis ses essais infructueux d'épopée socialiste, en passant par ses montages de paroles rapportées, jusqu'à ses collages littéraires les plus audacieux. Le statut qui est accordé au mot trouvé guide l'analyse, révélant le basculement progressif d'une représentation classique du réel, cadenassée par les exigences du réalisme socialiste, à une représentation conceptuelle, faite de l'agglomération de lambeaux de traditions culturelles marginales et hétérodoxes. 
5 Un succès indéniable de cette étude est qu'elle parvient à démontrer que, de manière paradoxale, l'anathème qui frappait les pratiques littéraires expérimentales en Europe Centrale aura eu sur elles un effet profitable. Alors que les poètes expérimentaux occidentaux s'avançaient toujours plus loin dans l'exploration formelle, et cela jusqu'à mettre en péril la notion même de sens, leurs confrères tchèques, Hrabal en tête, $\mathrm{y}$ puisèrent des techniques qui leur permettaient plus efficacement de dire le réel en dehors des sentiers balisés du réalisme socialiste. C'est à cette synthèse entre inventivité littéraire et volonté de décrire le réel, entre formalisme et historicité, que tient tout le talent de la plume de Hrabal.

6 La précision des analyses textuelles, rédigées dans un français limpide, témoigne d'une connaissance intime des sources. La fécondité des comparaisons ne laissera au lecteur qu'un léger regret, que leurs conclusions ne contribuent pas à une synthèse théorique plus développée, tant elles présentent d'intérêt. Assurément une lecture passionnante pour tous ceux qui s'intéressent à l'inventivité de la post-avant-garde face aux dogmes esthétiques!

INDEX

Index chronologique : communisme, XXe siècle

Index géographique : République tchèque, Tchécoslovaquie

Mots-clés : Littérature tchèque

\section{AUTEURS}

\section{THIBAULT DELEIXHE}

Doctorant en Lettres Slaves à l'Institut National des Langues et Civilisations Orientales (INALCO) de Paris 